\title{
Reinforced Microwave - Cured Acrylic Resin Denture Base Material with Glass Fibers
}

Radhwan H. Hasan BDS, MSc (Lect)

Mohammed A Abdulla BDS, MSc (Assist Lect)

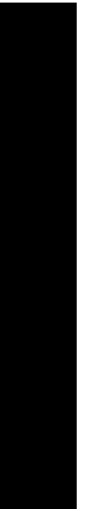

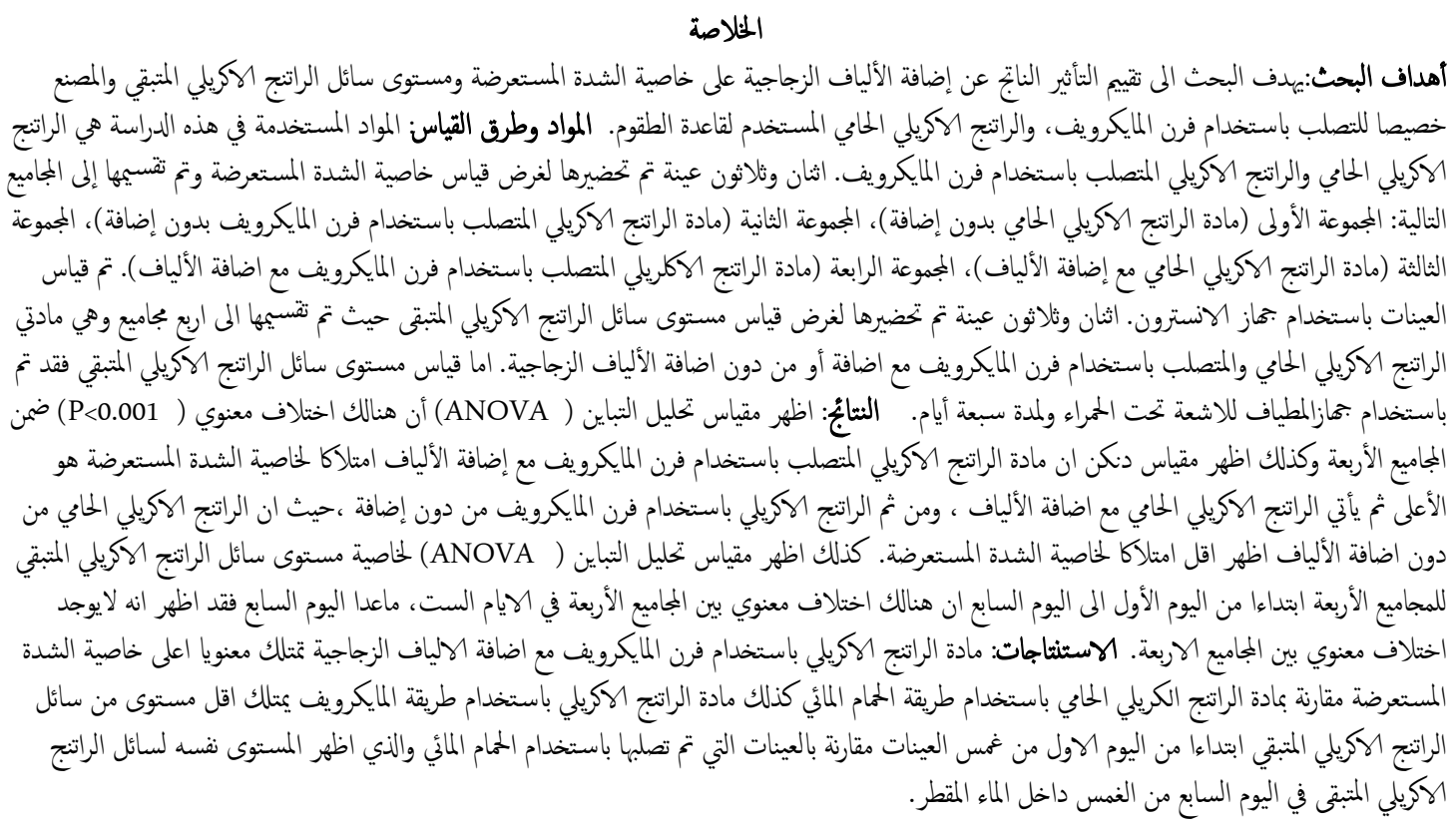

\section{ASTRACT}

AIMS: To evaluation the Effect of adding glass fibers on the transverse strength and the levels of the residual monomer of specially formulated acrylic resin to be cured by microwave and heat cured acrylic resin denture base materials. MATERIALS AND METHODS: The materials were used in this study heat cured acrylic resin and microwave cured acrylic resin which is formulated to be cured by microwave energy( Acronacrylic resin). Thirty two samples were prepared for transverse strength test and divided into the following groups Control group (I) heat cured alone, group (II) microwave cured alone, the group (III) heat cured+fibers, group (IV) microwave cured+fibers the transverse strength was evaluated by using an Instron testing machine. Thirty two samples were prepared for residual monomer test and divided into four groups water bath and microwave cured with and without glass fibers, the residual monomer was evaluated by using ultraviolet visible spectrophotometer for seven days. RESULTS: Transverse strength test: Statistical Analysis of Variance(ANOVA) shows that there is significant differences at ( $p>0.0001)$ among the four groups and Duncan's multiple range test showed that microwave cured + fibers significantly higher transverse strength followed by heat cured +fibers, microwave alone, while heat alone shows significantly lowest transverse strength. Residual monomer test: Analysis of variance(ANOVA) for the four groups from the first day of immersion in water until $7^{\text {th }}$ day shows that there are significant differences between the four groups in the all six days except the $7^{\text {th }}$ day shows that there are no significant differences among the four groups for the level of the residual monomer. CONCLUSIONS: Microwave cured acrylic resin with glass fibers have significantly higher transverse strength than that of acrylic resin cured by water bath, also microwave cured acrylic resin have significantly lower residual monomer content from the $1^{\text {st }}$ day of immersion when 
compared to that of water bath which show the same level of residual monomer at the $7^{\text {th }}$ day of immersion.

Key words: microwave cured, transverse strength, residual monomer, glass fibers

Hasan RH, Abdulla MA. Reinforced Microwave - Cured Acrylic Resin Denture Base Material with Glass Fibers. Al-Rafidain Dent J. 2010; 10(2):314-321.

Received: 21/4/2009

\section{INTRODUCTION}

One of the most widely used in prosthetic dentistry is polymethylemethacrylate (PMMA). The primary problem is its poor strength characteristics, including low impact and flexural strength ${ }^{(1,2)}$. Strengthening the acrylic resin prosthesis can be approached by modifying or reinforcing the resin ${ }^{(3)}$. One of the reinforcing techniques is the use of fibers; various types of fiber including carbon, Kevlar, glass, and polyethylene fibers have been tested. Glass fiber are the most common form of all used fibers; they improve mechanical properties of denture base polymers, have easy manipulation and they are esthetic $^{(4-6)}$, enhanced bonding to the resin matrix and ease of repair ${ }^{(1)}$. The residual concentration of methylmethacrylate (MMA) monomer has been examined widely for many reasons including polymerization conversion efficiency and its relation to physical and mechanical properties ${ }^{(7)}$. Numbers of methods have development to determine the level of residual monomer. Infrared spectroscopy ${ }^{(8)}$,and gas chromatography have been most commonly reported, but high performance liquid chromatography (HPLC) has also expanded its applications in analytical chemistry ${ }^{(9)}$.

AIMS : Evaluation the effect of adding glass fibers on the transverse strength and the levels of the residual monomer of specially formulated acrylic resin to be cured by microwave and heat cured acrylic resin denture base materials.

\section{MATERAILS AND METHODS}

The materials were used in this study heat cured acrylic resin which is formulated to be cured by water bath (RESPAL cross linked, Type I-Class1-ISO1567, Italy), microwaved cured acrylic resin which is formulated to be cured by microwave energy (Acronacrylic resin, microwavable GC-Japan), glass fibers (Chopped, Strand Mat thin, St, Helens, England). The study carried out with four groups which contained (8) specimens for each. Control group (I) consist of water bath heat polymerizing denture base resin specimens without any reinforcement (heat cured alone). The specimens in group (II) microwave polymerizing denture base resin specimens without any reinforcement (microwave cured alone). The specimens in group (III) water bath heat polymerizing denture base resin contained randomly glass fibers as reinforcing material (heat cured+fibers). The specimens in group (IV) microwave polymerizing denture base resin contained randomly glass fibers as reinforcing material(microwave cured+fibers) .

Addition of fibers: The glass fibers were added to the polymer powder in a random orientation at a concentration of $5 \%$ by weight using an electronic balance ${ }^{(10)}$. Glass fibers were wetted with methylmethacrylate monomer for 10 minutes then dried to ensure that all fibers would be completely saturated with monomer to facilitate their adhesion within the resin matrix ${ }^{(11)}$. The fibers and powder were mixed thoroughly to disperse the fibers ${ }^{(12)}$. The monomer was added to the polymer that containing the randomly distributed fibers together in ratio of 3:1 polymer/ monomer by volume or $2.5 / 1$ by weight according to manufacturer instructions. Mixing was done to make sure that all fibers were well wetted with monomer and evenly dispersed in the dough mixture.

Curing cycles:- For water bath technique acrylic resin was cured for 30 minutes at $70^{\circ} \mathrm{C}$ then 30 minutes at $100^{\circ} \mathrm{C}$ according manufacturer instructions, while for microwave technique acrylic resin was cured at 500watt for 3 minutes in domestic microwave oven (Panasonic, Batch No.NN- 
GX36WF, Korea) according manufacturer instructions .

Transverse strength test:

A-Test specimen:

Thirty two Rectangular samples with dimension of $65 \times 10 \times 2.5 \pm 0.03 \mathrm{~mm}$ in length, width, thickness respectively according to ADA specification ${ }^{(13)}$ were prepared, and all specimens were finished with 600 and 500 grit carbide bur to a final dimension $65 \times 10 \times 2.5 \pm 0.03 \mathrm{~mm}$. The width and thicknesses of all specimens were measured by a digital vernier caliper (LEZACO, ART. 2771, China).

B- Procedure: After conditioning of the tested samples in distilled water for 24 hours, the transverse strength of specimens was measured by using three- point loading on an Instron testing machine. The device was supplied with a central loading plunger and two supports with polished cylindrical surfaces $3.2 \mathrm{~mm}$ diameter placed $50 \mathrm{~mm}$ apart. The supports should be parallel to each other and perpendicular to the central line, the test specimens were held at each end of the two supports, and the loading plunger placed mid-way between the supports. The test was carried out with constant cross-head speed of $5 \mathrm{~mm} / \mathrm{min}$; the specimens were deflected until fracture occurred. The ultimate flexural strength (MPa) of each specimen was determined with the following formula ${ }^{(14)}$ :

F.S ( flexural strength $)=\frac{3 \times \mathrm{f} \times \mathrm{I}}{2 \times \mathrm{b} \times \mathrm{h}^{2}}$

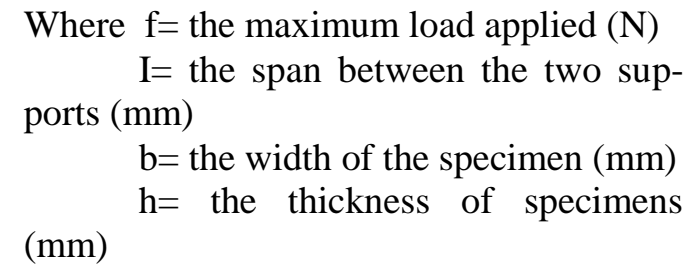

\section{Residual monomer test:}

A- Test specimens: Thirty two samples were prepared for this test, the dimension of acrylic resin specimens prepared for residual monomer test is $20 \times 20 \times 3 \mathrm{~mm}$ length, width, thickness respectively ${ }^{(15)}$. Each specimen was introduced in sealed glass flask contains $10 \mathrm{ml}$. distilled water at $37^{\circ} \mathrm{C}$ for $24 \mathrm{hs}$. for each sample. In an incubator, the supernatant were removed. The time dependant monomer concentration was followed by monitoring the amount of monomer present in supernatant medium using (CECIL 2000) ultraviolet visible spectrophotometer $(£=254 \mathrm{~nm})$ compared with pure monomer. The results were expressed as a percentage of released residual monomer mass with respect to the weight of specimens $(\% \mathrm{w} / \mathrm{w})^{(16)}$, daily evaluation of the specimen was carried until the $7^{\text {th }}$ day.

\section{RESULTS}

Transverse strength test: Means and standard deviations for all four groups: heat cured and microwave cured with and without fibers are shown in Table (1) and Figure (1), analysis of variance(ANOVA)

Table (1): Mean, Standard Deviation, and Duncan's Multiple Range Test of the Transverse Strength for the Four Groups of Acrylic Resins (heat cured and microwave cured).

\begin{tabular}{cccc}
\hline Types of acrylic resin & $\begin{array}{c}\text { Transverse strength }(\mathbf{M P a}) \\
\text { Mean } \pm \text { SD }\end{array}$ & Duncan's group & N \\
Microwave + fiber & $132.10 \pm 2.846$ & & \\
Heat cured + fiber & $122.60 \pm 2.914$ & A & 8 \\
Microwave alone & $118.30 \pm 3.433$ & B & 8 \\
Heat alone & $92.50 \pm 2.461$ & C & 8 \\
& & D & 8
\end{tabular}

$\mathrm{SD}=$ standard deviation, $\mathrm{N}=$ number of samples, groups with different letters=significant 


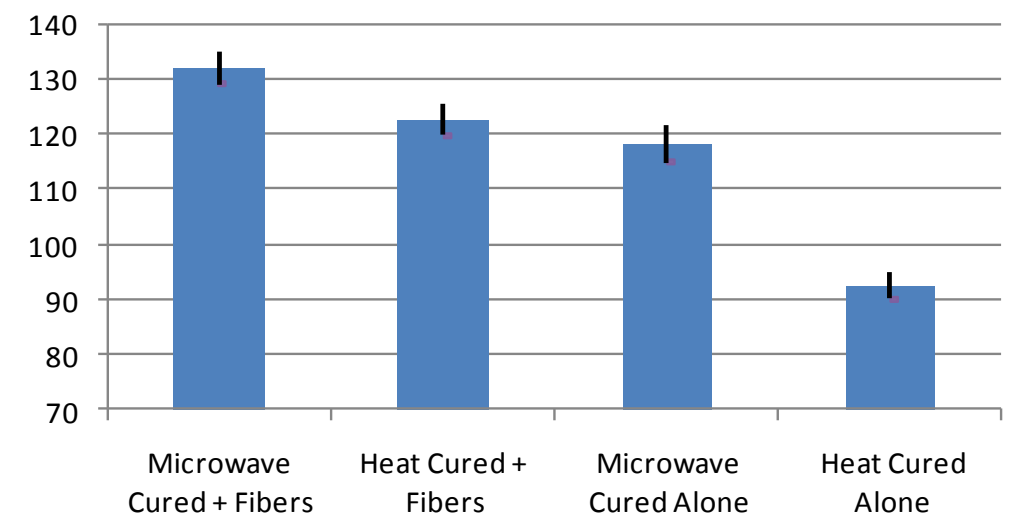

Figure(1) :Transverse Strength of Four Groups of Heat and Microwave Cured Acrylic Resin with or without Fibers.

Table (2) shows that there is significant differences at ( $p>0.0001)$ among the four groups. Duncan's Multiple Analysis Range Test Table (1) shows that microwave cured + fibers group shows significantly higher transverse strength $(132.10 \pm 2.846$
Mpa) followed by heat cured +fibers group(122.60 $\pm 2.914 \quad$ Mpa),microwave alone group $(118.30 \pm 3.433 \mathrm{Mpa})$ while heat alone group shows significantly lowest transverse strength $(92.50 \pm 2.461$ Mpa).

Table (2):Analysis of Variance (ANOVA) for Levels of Four Groups of Heat and Microwave Cured Acrylic Resin with or without Fibers.

\begin{tabular}{cccccc}
\hline Between the four groups & Sum of squares & Df & Mean square & F- value & P- value \\
& 8597.475 & 3 & 2865.825 & 332.913 & $0.000^{*}$
\end{tabular}

*Significant differences, $\mathrm{df}=$ degree of freedom

\section{Residual monomer test:}

Means and standard deviations of the level of residual monomer for the four groups of acrylic resin(heat cured ,microwave cured with and without fibers)within seven days are shown in Table (3). 
Table(3) : Mean, Standard Deviation, and Duncan's Multiple Range Test of ResidualMonomer for the Four Groups of Acrylic Resins (heat cured, microwave cured with and without fibers) within Seven Days.

\begin{tabular}{|c|c|c|c|c|}
\hline Days of testing & Acrylic resin & $\operatorname{Mean}(\mathrm{nm}) \pm$ SD & Duncan's group & $\mathbf{N}$ \\
\hline \multirow{4}{*}{ First day } & Heat alone & $0.3725 \pm 0.0196$ & $\mathrm{C}$ & 8 \\
\hline & Heat + fiber & $0.3396 \pm 0.0102$ & B & 8 \\
\hline & Microwave alone & $0.3629 \pm 0.0184$ & $\mathrm{C}$ & 8 \\
\hline & Microwave + fiber & $0.2624 \pm 0.0299$ & A & 8 \\
\hline \multirow{4}{*}{ Second day } & Heat alone & $0.2880 \pm 0.0169$ & $\mathrm{D}$ & 8 \\
\hline & Heat + fiber & $0.2599 \pm 0.0055$ & $\mathrm{C}$ & 8 \\
\hline & Microwave alone & $0.2250 \pm 0.0096$ & B & 8 \\
\hline & Microwave + fiber & $0.2133 \pm 0.0188$ & A & 8 \\
\hline \multirow{4}{*}{ Third day } & Heat alone & $0.2343 \pm 0.0193$ & $\mathrm{C}$ & 8 \\
\hline & Heat + fiber & $0.2333 \pm 0.0107$ & $\mathrm{C}$ & 8 \\
\hline & Microwave alone & $0.2084 \pm 0.0075$ & B & 8 \\
\hline & Microwave + fiber & $0.1680 \pm 0.0249$ & A & 8 \\
\hline \multirow{4}{*}{ Fourth day } & Heat alone & $0.1945 \pm 0.0304$ & $\mathrm{C}$ & 8 \\
\hline & Heat + fiber & $0.1605 \pm 0.0271$ & B & 8 \\
\hline & Microwave alone & $0.1391 \pm 0.0195$ & $\mathrm{AB}$ & 8 \\
\hline & Microwave + fiber & $0.1181 \pm 0.0169$ & A & 8 \\
\hline \multirow{4}{*}{ Fifth day } & Heat alone & $0.1474 \pm 0.0355$ & $\mathrm{C}$ & 8 \\
\hline & Heat + fiber & $0.1298 \pm 0.0278$ & $\mathrm{BC}$ & 8 \\
\hline & Microwave alone & $0.1108 \pm 0.0122$ & B & 8 \\
\hline & Microwave + fiber & $0.0539 \pm 0.0331$ & A & 8 \\
\hline \multirow{4}{*}{ Sixth day } & Heat alone & $0.663 \pm 0.2528$ & B & 8 \\
\hline & Heat + fiber & $0.0245 \pm 0.2664$ & A & 8 \\
\hline & Microwave alone & $0.0134 \pm 0.0031$ & A & 8 \\
\hline & Microwave + fiber & $0.295 \pm 0.0649$ & $\mathrm{AB}$ & 8 \\
\hline \multirow{4}{*}{ Seven day } & Heat alone & $0.0026 \pm 0.0141$ & A & 8 \\
\hline & Heat + fiber & $0.0217 \pm 0.0398$ & A & 8 \\
\hline & Microwave alone & $0.0051 \pm 0.0026$ & A & 8 \\
\hline & Microwave + fiber & $0.0030 \pm 0.0018$ & A & 8 \\
\hline
\end{tabular}

$\mathrm{SD}=$ standard deviation, $\mathrm{N}=$ number of samples, groups with different letters=significant

Analysis of variance (ANOVA) Table (4) for the four groups from the first day of immersion in water until $7^{\text {th }}$ day shows that there are significant differences between the four groups in the all six days except the $7^{\text {th }}$ day shows that there are no significant differences among the four groups for the level of the residual monomer.

Duncan's Multiple Analysis Rang Test Table(3) shows that within $1^{\text {st }}$ day of immersion in water, microwave cured +fibers group shows significantly lowest levels of residual mono$\operatorname{mer}(0.2624 \pm 0.0299)$ followed by heat cured+fibers $(0.33960 \pm 0102)$, while microwave alone $(0.3629 \pm 0.0184)$ and heat alone $(0.3725 \pm 0.0196)$ shows significantly higher level of residual monomer at the $1^{\text {st }}$ day, while at the $7^{\text {th }}$ day, the results of the present study shows that there are no significant differences in the level of the residual monomer among all four groups Table (4). 
Table(4) : Analysis of Variance (ANOVA) for levels of Four Groups of Acrylic Resin with or without Fiber within Seven Days.

\begin{tabular}{cccccc}
\hline Days of testing & Sum of squares & df & Mean square & F- value & P- value \\
First day & 0.060 & 3 & 0.020 & 46.108 & $0.000^{*}$ \\
Second day & 0.028 & 3 & 0.009 & 70.878 & $0.000^{*}$ \\
Third day & 0.023 & 3 & 0.008 & 26.378 & $0.000^{*}$ \\
Fourth day & 0.025 & 3 & 0.008 & 14.588 & $0.000^{*}$ \\
Fifth day & 0.039 & 3 & 0,013 & 16.023 & $0.000^{*}$ \\
Sixth day & 0.013 & 3 & 0.004 & 3.013 & $0.047^{*}$ \\
Seventh day & 0.002 & 3 & 0.001 & 1.676 & $\mathbf{0 . 1 9 5}$ \\
\hline
\end{tabular}

*significant differences

\section{DISCUSSION}

Most of the researches which evaluate the properties of acrylic resin cured by microwave energy, were use acrylic resin formulated to be cure by water bath technique and that is why different results were obtained, while in this study, acrylic resin which is especially formulated to be cured by microwave energy was used.

Transverse strength:

The transverse strength (flexural strength) of a material is a combination of compressive, tensile and shear strengths. As the tensile and compressive strength increase, the force required to fracture the material also increase (17). Flexural strength tests were considered to be relevant to the loading characteristics of a denture base in clinical situation ${ }^{(18)}$. Fracture load applied to the specimens in this type of test is similar to the load that affects the maxillary complete denture in situ ${ }^{(19)}$. If fibers are to be used to strengthen polymer material ,optimal adhesion between the fibers and the polymer matrix is essential .Impregnation of reinforcing fibers with resin allows fibers to come into contact with the polymer matrix ${ }^{(20,21)}$, the result of the present study Figure(1) showed that glass fibers addition significantly increase transverse strength of acrylic resin (heat cured and microwave cured) and this is could considerably enhance the transverse strength of dental polymers, which could due to proper impregnation of fibers with monomer.

The polymer-pre impregnation of the glass fiber reinforcements tested in this study seemed to have resolved the problem of impregnating reinforcing fibers with resin of polymer matrix. When acrylic resin polymer powder and monomer liquid were mixed, monomers dissolved and swelled the surface of the powder beads. This plasticized the reinforcement and made it possible to form the reinforcement and place it into the desired region ${ }^{(6)}$.

The results of this study Figure (1) and Table (2) indicated that the fiberreinforced polymers are successful in their application primarily because of their specific modulus and specific strength. Because the modulus of elasticity of glass fiber is very high, most of the stresses are received by them without deformation and the increasing in strength is due to transfer of stress from the weak polymer matrix to the fibers that have a higher tensile strength ${ }^{(22)}$. Thus, in this study, glass fibers reinforced specimens exhibited better flexural strength than the other resin specimens groups, this is agreement with Vojdani and Khaledi ${ }^{(11)}$, John et al. ${ }^{(17)}$, Marei ${ }^{(23)}$, Hedzelek and Gajdus ${ }^{(24)}$, but disagreement with a study done by Chen $e t$ $a l .{ }^{(25)}$ demonstrated that transverse strength did not changed significantly with resin mixed with glass fibers when compared with groups without fibers. From the result obtained Figure (1) the high strength observed in microwave cured resin reinforced with glass fibers followed by heat cured with fibers then microwaved cured alone and finally heat cured alone. This agreement with Nagai et al. ${ }^{(26)}$ and Polyzois et al. ${ }^{(27)}$.

\section{Residual monomer:}

For the microwave cured acrylic resins(which is especially formulated to be 
cured by microwave energy), it has been demonstrated that the temperature developed during the reaction is not constant, it increases quickly at the beginning goes through a maximum and then decay, being able to reach peaks of the order of 150$200^{\circ} \mathrm{C}$, this may effect the ratio of polymerization and the conversion degree of acrylic resin and this has direct effect on reducing residual monomer ${ }^{(28)}$. Different polymerization methods have been used, heat, microwave energy ${ }^{(29)}$, microwave irradiation has the advantages of reducing time of cured, a bigger homogeneity of the mixture and the achievement of a prosthetic material with excellent adaptation, the degree of conversion is the most important characteristic, on account of the high residual monomer levels that could be un reacted. It is presence (monomer) has an adverse effect on physical and mechanical properties ${ }^{(30)}$,as well as on the biocompatibility. The polymerization reaction never reaches $100 \%$ conversion and monomers remain free within the material from which can be release to the oral cavity ${ }^{(15)}$.

From the results obtained in this study Tables 3,4 showed that the microwave cured acrylic resin with fibers and without fibers has significantly lowest level of residual monomer from the first day of immersion, but the heat cured alone has the highest level of residual monomer from the first day of immersion, while the $7^{\text {th }}$ day, there is no significant differences in residual monomer. The authors notice that the monomers released to the water that have not reacted during the polymerization process that's to say both MMA and the cross-linking agent, and those not release to the aqueous media can stay in the matrix resin as pending chains ${ }^{(31)}$.

It is obtained that the application of glass fiber to polymer during mixing to form a polymer monomer matrix, the monomer seems to be reduced (redce L/ P ratio) high viscosity than the manufacturer instruction for the monomer polymer ratio which is in turn, the level of tested residual monomer seems to be the low level in groups of heat and miocrowaved reinforced resin with fibers than the non reinforced resins. This findings agreement with Yunus et al ${ }^{(30)}$ and Byraktar et al. ${ }^{(32)}$.

\section{CONCLUSIONS}

Microwave cured acrylic resin with glass fibers have significantly higher transverse strength than that of acrylic resin cured by water bath, also microwave cured acrylic resin with glass fibers have significantly lower residual monomer content from the $1^{\text {st }}$ day of immersion when compared to that of heat cured acrylic resin (with and without fibers) which show the same level of residual monomer at the $7^{\text {th }}$ day of immersion.

\section{REFERENCES}

1. Jagger DC ,Harrison A, Jankd KD. Review the enforcement of dentures. $J$ Oral Rehabil. 1999;26:185-194.

2. Robinson JG, Mc Cobe JF. Impact strength of acrylic resin denture base materials with surface defects. Dent Mater. 1993;9:355-360.

3. Matsukawa S, Hoyakawa T, Nemoto K. Development of high -toughness resin for dental applications .Dent Mater. 1994; 10:343-346.

4. Miettnen VM, Vallittu PK. Water sorption and solubility of glass fiber reinforced denture polymethyl methacrylat resin .J Prosthet Dent. $1997 ; 77: 531-534$

5. Uzun G, Hersek N, Tincer T. Effect of five woven fiber reinforcement on the impact and trans force strength of a denture base resin .J Prosthet Dent. 1999;81:616-620.

6. Vallitu PK . Flexural properties of acrylic resin polymers resin forced with unidirectional and woven glass fibers . J Prosthet Dent. 1999;81:318-326.

7. Dogan A, Bek N, Cevik N, Usanmaz A. The effect of preparation conditions of acrylic denture base materials on the level of the residual monomer.mechanical properties and water absorption .J Dent. 1995;23,313-318 .

8. Douglas W, Basker R. The determination of the residual monomer in polymethylmethacrylate denture base resins. J Mater Sci mater Med. 1978; 13:2600-2604 .

9. Sadamori S ,Kotani H ,Hamada T. The usage period of denture and their residual monomer contents . J Prosthet Dent. 1992; 68:374-376

10. Al-Nema L M. Evaluation of some mechanical properties of reinforced acrylic resin denture base material( in vitro 
study).MSc. Thesis, University of Mosul. 2005.

11. .Vojdani M and Khaledi AR. Transverse strength of reinforced denture base resin with metal wire and E-glass fibers $J$ Dent. 2006 ;3(4):167-172 .

12. Karacaer O, Polat TN, Tezvergil A,Lassila LV, and Vallittu PK. The effect of length and concentration of glass fiber on the mechanical properties of an injection and compression molded denture base polymer. J Prosthet Dent. 2003 ;90:385-393.

13. American Dental Association. Guide to dental material and devices $7^{\text {th }}$ edition Chicago .ADA 1975; pp.20-214 .

14. Aydin C, Yilmaz H, Caglar A .Effect of glass fiber reinforcement on the flexural strength of different denture base resin .Qunit Int.2002;33:457-463.

15. Azzarri MJ ,Cortizo MS ,Alessandrini J L. Effect of the curing condition on the properties of an acrylic denture base resin microwave polymerized . J Dent. 2003;31 :463-468.

16. De Oliveira MB ,Leon LT , Del belcury AA, Consani S. Influence of number and position of flasks in the monomer release,Knoop hardness and porosity of a microwave cured acrylic resin .J Oral Rehabil. 2003;30:1104-1108 .

17. John J, Shiraputrappa A, Gangadhar SA and Shah I. Flexural strength of heat polymerized poly methyl methacrylate denture resin reinforced with glass, aramid, or nylon fiber .J Prosthet Dent. 2001;86:424-427.

18. Jagger DC , Jagger RG , Allen SM , and Harrison A . An investigation into the transverse and impact strength of high strength denture base acrylic resins .J Oral Rehabil. 2002;29,263.

19. Vallittu PK, Lassila VP, Lappalainen R. Transverse strength and fatigue of denture acrylic glass fiber composite .Dent Mater. $1994 ; 10: 116-121$.

20. 20. Vallittu PK. Impregnation of glass fiber with polymethyl methacrylate by using a powder coating method. Appl Composite Mater. 1995;2:51-58.

21. Kanie T,Arikawa H, Fujii K, Ban S. Mechanical properties of woven glass fiber-reinforced composites. Dent Mater. 2006;25:377-381.
22. Hamza TA, Rosenstiel SF , EL-Hosary MM , and Ibraheem RM. Fracture resistance of fiber -reinforced PMMA interim fixed partial dentures. J Prosthodont. 2006;15:223-228 .

23. Marei M. Reinforcement of denture base resin with glass fillers. J Prosthodont. 2005; 8(1):18-26.

24. Hedzelek W and Gajdus P. Mechanical strength of an acrylic resin palatal denture base reinforced with a mesh or bundle of glass fibers .Int $J$ Prosthodont .2007;20(3):311-312 .

25. Chen SY, Liarg WM, and Yen PS. Reinforcement of acrylic denture base re$\sin$ by incorporation of various fibers . $J$ Biome Mat. 2008;58 (2), :203- 208 .

26. Nagai E ,Otani K, Satoh Y .Repair of denture base resin using woven metal and glass fiber :effect of methylene chloride pretreatment .J Prosthet Dent.2001;85 :496-500 .

27. Polyzois GL, Tarantili PA, Frangon MJ ,Andreopoulos AG. Fracture force ,deflection at fracture and toughness of repaired denture resin subjected to microwave polymerization or reinforced with wire or glass fiber. J Prosthet Dent. 2001 ;86:613-619.

28. Jacob J, Chia LH, Boey FYC. Microwave polymerization of poly(methylacrylate):conversion studies at variable power. $J$ Appl Poly. Scin. 1997;63:787-797

29. Smith LT, Powers JM, Ladd D. Mechanical properties of new denture resins polymerized by visible light, heat and microwave energy. Int $J$ Prosthodont. 1992;5:315-320.

30. Yunus N, Harrison A, and Huggett R. Effect of microwave irradiation on the flexural strength and residual monomer levels of an acrylic resin repair material $J$ Oral Rehabil. 2007;21: 641- 648.

31. Ferracane J L. Elution of leachable component from composites $\mathrm{J}$ Oral Rehabil. 1994;21: 441-452.

32. Bayraktar G, Duran O, and Guvener B. Effect of glass fiber reinforced on residual methylmethacrylate content of denture base polymers J Dent. 2003 ;31: 297-302 